\title{
ANNOUNCEMENT
}

\section{VNS Young Investigator Award}

Dr. Greg Schwartz was awarded the 2012 VNS Young Investigator Award at the biennial FASEB meeting on Retinal Neurobiology \& Visual Processing held in Steamboat Springs, Colorado. Dr. Schwartz's poster was selected from among 46 eligible poster presentations. The work that Dr. Schwartz presented was conducted in collaboration with Dr. Will Grimes in the laboratory of Dr. Fred Rieke at the University of Washington. In this study, Schwartz and coworkers found an unexpected switch in spatial integration properties of ON ganglion cells in mouse retina, from linear "X-like" integration at low light levels where rod signaling dominates, to nonlinear "Y-like" behavior at higher light levels where cones contribute. Furthermore, they demonstrated that the site of the switch is the output synapse of the ON cone bipolar cell, which changes its maintained rate of glutamate release depending on average light intensity. These results show that changes in the release properties of bipolar-cell ribbon synapses can cause a substantial shift in how retinal ganglion cells spatially integrate their inputs.

The Editors would like to thank the members of the selection committee for serving in this capacity.

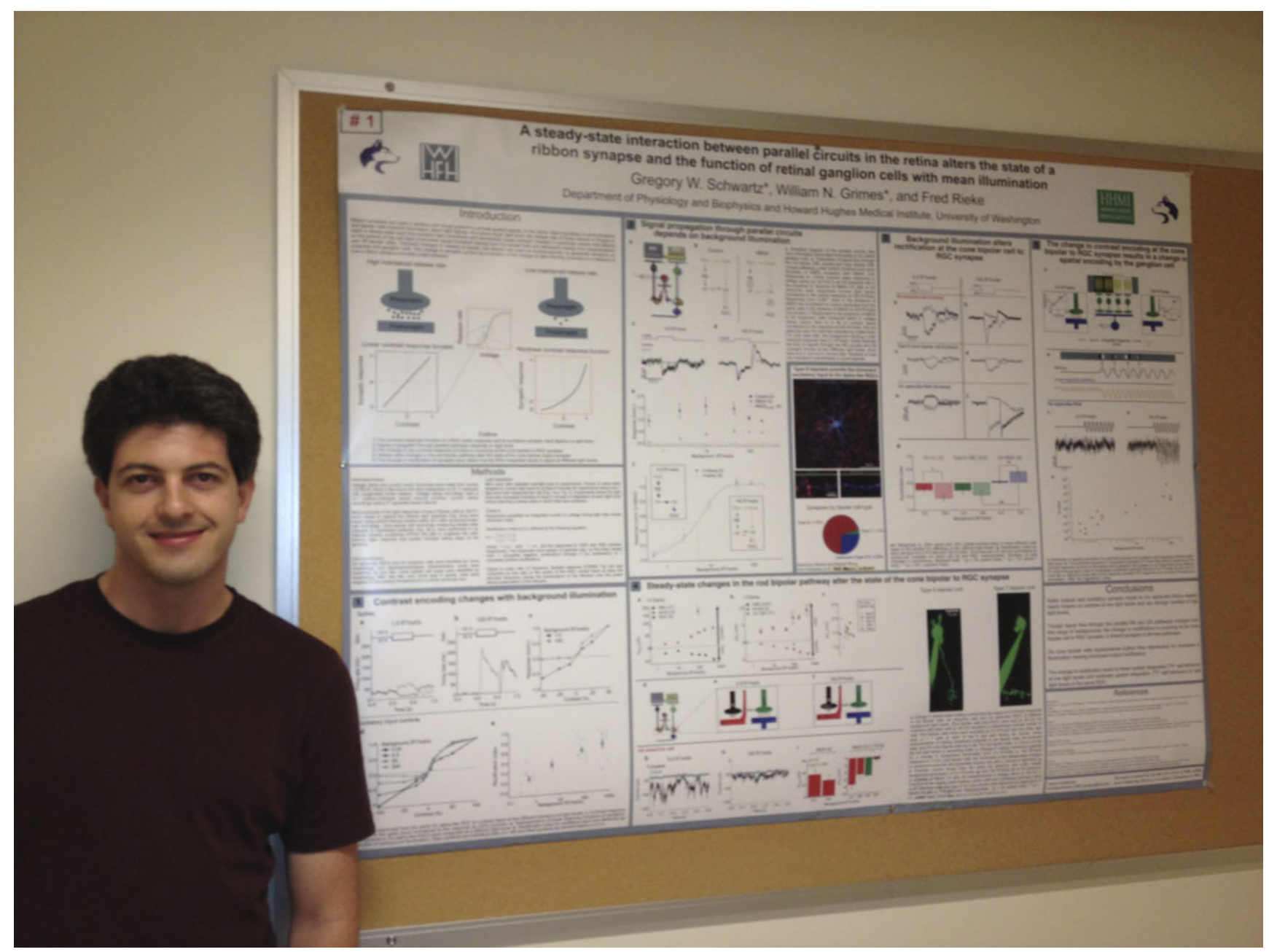

The recipient of the 2012 VNS Young Investigator Award, Greg Schwartz, and his 2012 FASEB poster. 